\title{
PREVENTATIVE TREATMENTS FOR CONTROL OF FUNGUS GNATS AND SHORE FLIES
}

\author{
C.W. VAN EPENHUIJSEN, B.B.C. PAGE and J.P. KOOLAARD
}

\author{
New Zealand Institute for Crop \& Food Research Limited, Private Bag 11 600, \\ Palmerston North
}

Corresponding author: vanepenhuijsenk@crop.cri.nz

\begin{abstract}
Preventative treatments for control of fungus gnats (Bradysia sp. nr. paupera, Diptera: Sciaridae) and shore flies (Scatella tonnoiri Hendel, Diptera: Ephydridae) were carried out by drenching potted tobacco plants with diflubenzuron and Bacillus thuringiensis var. israelensis (Bti). The treatments were applied at different rates and times and compared with the use of sand and sawdust toppings to cover the potting mix. Diflubenzuron treatments applied at three and nine weekly intervals and Bti applied at weekly intervals gave the lowest numbers of fungus gnats. The sand topping for the control of shore flies gave significantly better results than the untreated control.
\end{abstract}

Keywords: Bradysia, Bti, diflubenzuron, fungus gnat, Scatella, shore fly.

\section{INTRODUCTION}

Adult fungus gnats and shore flies can severely damage greenhouse plants. They often occur together and can be misidentified by growers. Shore flies are distinguished by having white spots on each wing while fungus gnats have a diagnostic $\mathrm{Y}$ shape in their wing venation. The larvae of fungus gnats are white with shiny black heads while shore fly larvae are dark coloured and have two spiracles at the posterior end of their body.

Potting mix that has a high level of fresh organic matter and a high moisture level promotes fungal and algae growth in the medium and provides ideal breeding conditions for both insects. Populations of fungus gnats and shore flies increase when plants are kept in the same containers for long periods, as algae and mosses often develop on top of the potting medium.

Shore flies

Shore fly larvae are algae eaters. They do not feed on plant roots or stems but they deposit faecal droplets on the foliage of young plants and may transmit spores of Fusarium oxysporum (Corbaz \& Fisher 1994). They can be so abundant that they become an irritant to people working in the greenhouse.

Fungus gnats

The larvae of some species of fungus gnats damage plants by feeding on root hairs and tunnelling within plant stems, thus killing seedlings. They may also be vectors of Verticillium spores (Kalb \& Millar 1986).

Insecticides for control of fungus gnats are applied as a coarse spray or through overhead sprinklers (Anon. 1995). Treatment of potting mix with diflubenzuron at $0.25 \mathrm{~g} /$ litre (Martin \& Workman 1999) is regarded as an industry standard. Covering the growth medium to make it unattractive to adult flies or impenetrable for newlyhatched larvae (Hungerford 1916) is often mentioned (Martin 1995) but has never been properly tested for fungus gnat or shore fly control.

In this trial we aimed to develop best practice recommendations for fungus gnat and shore fly control in plants growing in potting mix, to define how long some chemical treatments remain effective, and to determine the effect of covering potting mix with sand or sawdust. 


\section{METHODS}

Tobacco seeds (Nicotiana tabacum) cv. Brazilian Blend were sown in a greenhouse and transplanted, when three months old, into $90 \mathrm{~mm}$ plastic pots $\left(350 \mathrm{~cm}^{3}\right)$ with saucers. A standard potting mix (bark:peat:pumice 35:30:35) was used, to which was added $20 \mathrm{~g}$ blood and bone per litre of mix to attract fungus gnats (Hungerford 1916). The plants were laid out on benches in a randomised block design with eight replicates, each consisting of twenty one plants, three plants for each of seven treatments (Table 1). Within each block the plants were randomly placed around a capsicum plant (Solanum annuum) which served as the source of flies. The capsicum plants were cut back to pot level as when aphids started to infest them. The number of leaves per tobacco plant was kept at three from two months after sowing and all leaves more than $140 \mathrm{~mm}$ long were removed to ensure that the potting mix did not dry out.

\section{Treatments}

A $22 \mathrm{~mm}$ layer of river sand (71\% of the particles passed through a $1.2 \mathrm{~mm}$ sieve) or $22 \mathrm{~mm}$ of sawdust (largest piece $5 \mathrm{~mm}$ ) from untreated pine (Pinus radiata) were used as toppings over the potting mix. The pesticides used were a microbial pesticide, Bacillus thuringiensis var. israelensis, Bti (1200 ITV per milligram) and a growth regulator, diflubenzuron ( $250 \mathrm{~g}$ ai $/ \mathrm{kg}$ ) (Table 1). Fungus gnats were cultured in a mixture of ground soaked beans in peat (Gillespie 1986) and the larvae were released in the pots containing capsicum plants. In addition, shore flies and fungus gnats were sucked up with a handheld vacuum cleaner in an adjacent greenhouse and released at random in the greenhouse with the tobacco plants over a period of 3 weeks.

The pesticides were applied to the pots in $50 \mathrm{ml}$ of water per pot via a Cambrian compressed air sprayer when the plants were $200 \mathrm{~mm}$ high.

TABLE 1: Treatments applied to potted tobacco plants.

\begin{tabular}{lcccc}
\hline Treatment & Rate & $\begin{array}{c}\text { Total number } \\
\text { of applications }\end{array}$ & Interval (weeks) & $\begin{array}{c}\text { Last application } \\
\text { date }^{1}\end{array}$ \\
\hline Control (water) & - & - & - & - \\
sawdust (topping) & - & - & - & - \\
sand (topping) & - & - & - & - \\
Bti & $1.6 \mathrm{~g} / 1$ & 4 & 3 & $02 / 04$ \\
Bti & $0.5 \mathrm{~g} / 1$ & 8 & 1 & $26 / 03$ \\
diflubenzuron & $1.25 \mathrm{ml} / 1$ & 2 & 3 & $03 / 04$ \\
diflubenzuron & $0.625 \mathrm{ml} / 1$ & 4 & 3 & $02 / 04$ \\
\hline
\end{tabular}

${ }^{1}$ Initial application of drench was made on 30/01/1998.

\section{Watering}

Initially each plant was given $150 \mathrm{ml}$ water three times a week on top of the potting mix. Later when the number of leaves was reduced to three per plant this was reduced to $50 \mathrm{ml}$. This ensured the potting mix stayed moist. Surplus water remained in the saucers. All plants received the same quantity of water, taking into account the amount applied as part of the treatments. When the treatment and watering dates coincided, water was applied the day after the treatment.

\section{Assessment of larval numbers}

Numbers of fly larvae were assessed 33 and 52 days after the first treatment. The third assessment took place 7 days after the last pesticide application. For each assessment one pot per treatment in each block was chosen randomly. To assess numbers of larvae in the pots the plants were cut back to $50 \mathrm{~mm}$ high and the top $22 \mathrm{~mm}$ layer of potting mix and plant roots was sawn off with a small hacksaw. The larvae were then extracted from this layer. The sawdust and sand toppings were removed before sawing off the 
layer. The larvae, pupae and fine potting mix were removed by washing the sample under running water through a sieve (openings $1.4 \mathrm{~mm}^{2}$ ) over a 5 litre jug. The washing process was stopped when the jug was full with a mix of water and fine bark mix. The 5 litre of fine bark particles and water was then poured through a nylon $(300 \mu \mathrm{m})$ sieve.

The sieve was left for 15 seconds with the nylon mesh resting on a paper towel and then placed in a round plastic container (inside diameter $130 \mathrm{~mm}$, height $40 \mathrm{~mm}$ ) partly filled with a saturated solution of $100 \%$ magnesium sulphate. Both sieve and container were then placed under a microscope. The solution containing the finest particles of the bark mix was stirred with a fine art brush to facilitate searching. The floating larvae and pupae were then removed and numbers of each insect were recorded separately. The number of larvae and pupae in the toppings were counted for $30 \%$ of the plants.

\section{Statistical analyses}

To examine the cumulative effect of each treatment over the whole period of the investigation, the data from the three pots per treatment within each block were added together for analysis. Fungus gnat and shore fly data were analysed separately. A generalized linear model with a logarithmic link function and negative binomial error distribution was fitted to both data sets. There was a good fit of these models to the data, with a residual mean deviance of 1.02 using an aggregation parameter of 2.2 for fungus gnats and a residual mean deviance of 1.11 using an aggregation parameter of 1.0 for shore flies. The number of shore flies for all treatments was low, but some significant differences $(\mathrm{P}<0.05)$ between the treatments were found. Predicted mean counts together with $95 \%$ confidence intervals were obtained from the fitted statistical models, and are presented in Figs 1 \& 2. Genstat was used for statistical analyses.

\section{RESULTS}

Fungus gnats

The average number of fungus gnat larvae and pupae in the top layer of the three control pots was 142.5 with a highest count of $125 / 100 \mathrm{~cm}^{3}$. The two diflubenzuron treatments and the low dose of Bti with weekly repetitions gave fewer $(\mathrm{P}<0.05)$ gnat larvae than the other four treatments (Fig. 1), with numbers in the low dose of Bti

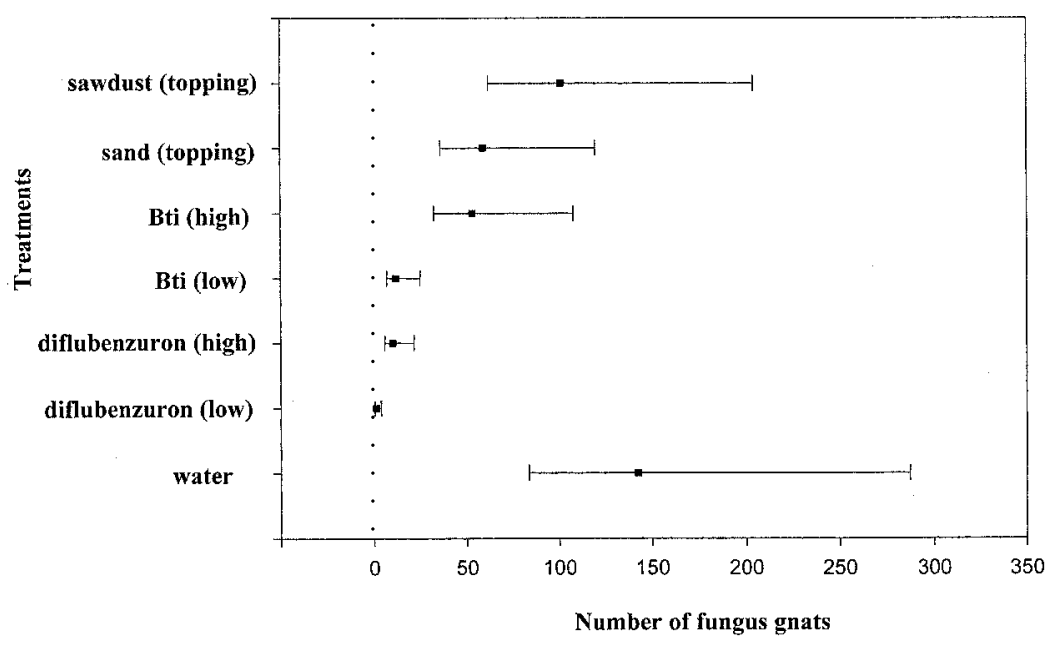

FIGURE 1: Numbers of fungus gnat larvae and pupae found in the top $22 \mathrm{~mm}$ of potting mix. Mean values and $95 \%$ confidence intervals are shown. 
significantly lower than even the diflubenzuron treatments. The high dose of Bti applied at 3-week intervals gave lower fungus gnat counts than the untreated control $(\mathrm{P}<0.05)$. The sand topping treatment gave fewer fungus gnats $(\mathrm{P}<0.05)$ than the untreated control.

Fungus gnat larvae and pupae were found in both topping treatments but in much higher numbers in the sawdust topping, although the difference was not significant $(P>0.05)$. The mean number of fungus gnats (adults and larvae) in the sawdust (8.75) was higher $(\mathrm{P}<0.05)$ than for the sand topping.

Shore flies

Shore fly larvae were not found in the sand and sawdust topping treatments but pupae were present in both. The number of shore flies found for all treatments was low (0-48/ 3 pots (Fig. 2). The treatments with sawdust and sand had lower numbers of shore flies than the other treatments, especially the water control, Bti (high dose) and the diflubenzuron (low dose) $(\mathrm{P}<0.05)$. The mean number of shoreflies (pupae only) per pot for the sand topping (2.75)was more than twice the number for sawdust (1.25 per pot $)(\mathrm{P}=0.07)$.

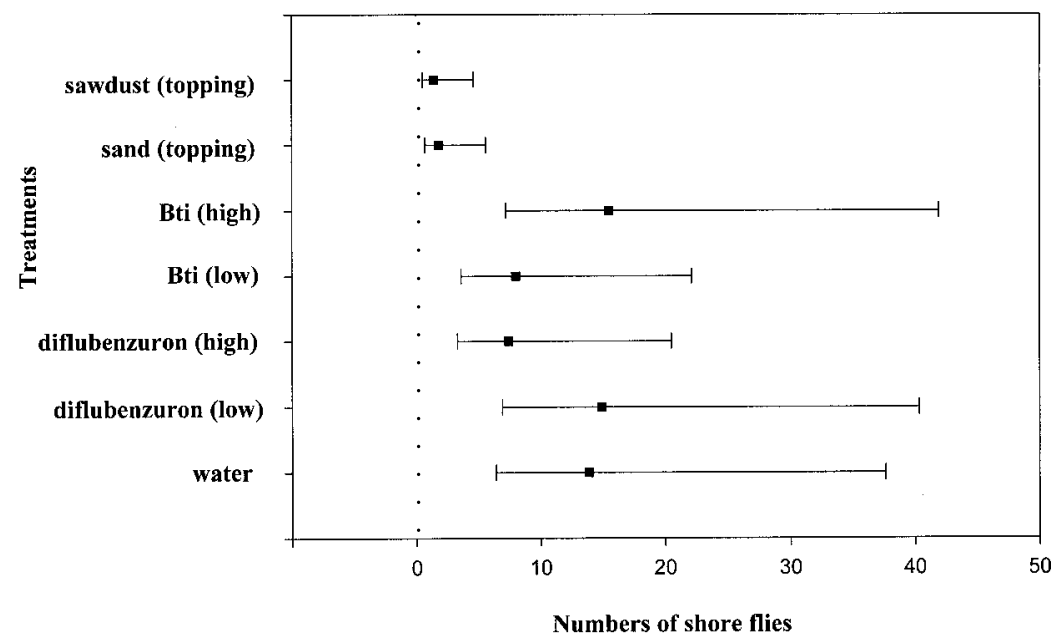

FIGURE 2: Numbers of shore fly larvae and pupae found in the top $22 \mathrm{~mm}$ of potting mix. Mean values and $95 \%$ confidence intervals are shown.

\section{DISCUSSION AND CONCLUSIONS}

If all recommended hygiene, screening and watering procedures are adhered to, growers should only experience minor problems with fungus gnats in potted plants. However this advice is difficult to implement fully. The biological control agents, Hypoaspis and Steinernema, used overseas are not commercially available in New Zealand. There is a need therefore for easily implemented methods of control of these pests.

This investigation demonstrated that diflubenzuron and Bti applications can reduce numbers of both pests. Of the three successful treatments, three weekly applications of diflubenzuron at $0.625 \mathrm{ml} / \mathrm{l}$ gave the least variable levels of control for fungus gnats. Frequent applications of both products may be necessary in production systems to ensure that new plant trays are treated before entering the greenhouse.

During the investigation the growing medium remained moist making it easy for newly hatched larvae to pass through the toppings used and reach the potting mix below. They did however reduce numbers of shore flies, and the sand topping appeared to have reduced 
numbers of fungus gnats associated with it. The technique warrants further investigation particularly if a method of keeping the toppings drier can be implemented.

\section{ACKNOWLEDGEMENTS}

We wish to thank Alan Cliffe, Nufarm Ltd, for the supply of diflubenzuron (Dimilin $25 \mathrm{~W}$ ) and Bti (VectoBac 12AS) and his advice on the rates to be used. Dr Nick Martin gave us valuable advice and Peter Workman supplied us with the tobacco seeds. Allied Concrete (Levin) is gratefully acknowledged for the supply of sand, as is Crighton Sawmill (Levin) for the supply of sawdust. Identifications for Bradysia sp. and Scatella sp. were provided respectively by Mark Bullians and Alan Flynn (AgriQuality N.Z. Ltd. Auckland).

\section{REFERENCES}

Anon. 1995: Vectobac Biological insecticide vector control. Abbott laboratories, North Chicago, Illinois 60064 USA. AGR4910/R1. 4 p

Corbaz, R.; Fisher, S. 1994: La mouche Scatella stagnalis (Fall) (Diptera, Ephydridae) responsable de la dispersion de Fusarium oxysporum $f$. sp. lycopersci dans les cultures de tomates hors sol. Revue Suisse Vitic. Arboric. Hortic. 26 (6): 383-385.

Gillespie, D.R. 1986: A simple rearing method for fungus gnats Corynoptera sp. (Diptera: Sciaridae) with notes on life history. J. Entomol. Soc. Brit. Columbia 83 (31): 4548.

Hungerford, H.B. 1916: Sciara maggots injurious to potted plants J. Econ. Entomol. 9: 538-549.

Kalb, D.W.; Millar, R.L. 1986: Dispersal of Verticilium albo-atrum by the fungus gnat (Bradysia impatiens). Plant Disease 70: 752-753.

Martin, N.A. 1995: Weapons in war on fungus gnats. On the cutting edge of controlling fungus gnats. Flowers New Zealand, April: 14-15.

Martin, N.A.; Workman, P.J. 1999: A comparison between preventative and curative soil treatments for control of fungus gnats. Proc. 52nd. N.Z. Plant Prot. Conf.: 5055 . 